\title{
The Price of Shared Accommodation in Bratislava and Its Dependence on the Number of Visitors to Bratislava
}

DOI 10.18267/pr.2021.krn.4816.10

\author{
Jakub Kóňa \\ ORCID iD: 0000-0002-8000-6773 \\ jakub.kona@euba.sk \\ University of Economics in Bratislava, Faculty of Commerce, Department of Services \\ and Tourism \\ Bratislava, Slovakia
}

\begin{abstract}
Through shared accommodation, the shared economy occupies a full position in many economies of the world and the extent of its influence can be expressed in various ways. In addition, the price of accommodation appears to be a sufficiently objective, measurable, and comparable element with other statistical tools of the economic environment. In the article, we use statistical methods of correlation and regression analysis to express the relationships between the dependent variable in the form of the price of shared accommodation in Slovakia and the number of visitors, which thus represent a separate variable. The results are expressed numerically and graphically.
\end{abstract}

Keywords: Airbnb Price, Airbnb in Bratislava, Shared Accommodation Prices

JEL Classification codes: L83

\section{INTRODUCTION}

Over the last decade, we have witnessed the growing popularity of the sharing economy, literally on a global scale (Sundararajan, 2016). Peer-to-peer (P2P) shared accommodation platforms have experienced a particularly strong increase in users and thus occupy a significant place in the sharing economy (PwC, 2015). Both parties benefit from the P2P system of shared accommodation - users can offer their services for a financial reward, while the platform administrator ensures the functionality of the place of the conflict of supply and demand (Botsman, 2013) and receives a commission for it. One of the most popular and most frequently discussed examples of this mechanism is Airbnb (Guttentag, 2015), with more than 2.9 million hosts and more than 7 million seats offered in 100,000 cities, respectively. in 220 countries (Deane, 2020). Similar shared accommodation services are offered by competitors such as Houseswap, OneFineStay, Windmu, Couchsurfing, and others. (Dredge \& Gyimóthy, 2015).

Platforms such as Airbnb allow individuals to take on the role of micro-entrepreneurs and act as hosts offering accommodation to tourism participants for a fee (Sundararajan, 2014). In fact, depending on the attractiveness of the offer, the location, the type of accommodation offered (dormitory, private room, or entire unit), and the length of the rental (in the order of days, weeks, or even months), Airbnb hosts can generate significant revenue (Jung et al., 2016). The hosts thus have the opportunity for self-employment and its amount depends on the large demand for their supply. Demand can be influenced by changing the price of supply, the development of which should dynamically adapt to changes in the market (Singh, 2012). 
But what should the providers of shared accommodation in the capital of Slovakia follow in pricing? How to analyze market developments and react flexibly to current market conditions by choosing the appropriate price change? Changes in the price level of the offer of shared accommodation may depend on the development of other indicators of tourism, and it is this idea that encouraged us to carry out the research described below in the following sections of this article.

\section{LITERATURE REVIEW}

Accommodation statistics mediated by the Airbnb platform record annual growth and it could be said that the constantly growing curve of visitors staying in Bratislava (Fig. 1) only copies the global trend.

\section{Fig. 1 Number of overnight stays and number of Airbnb visitors (in Bratislava, respectively in America and Europe)}

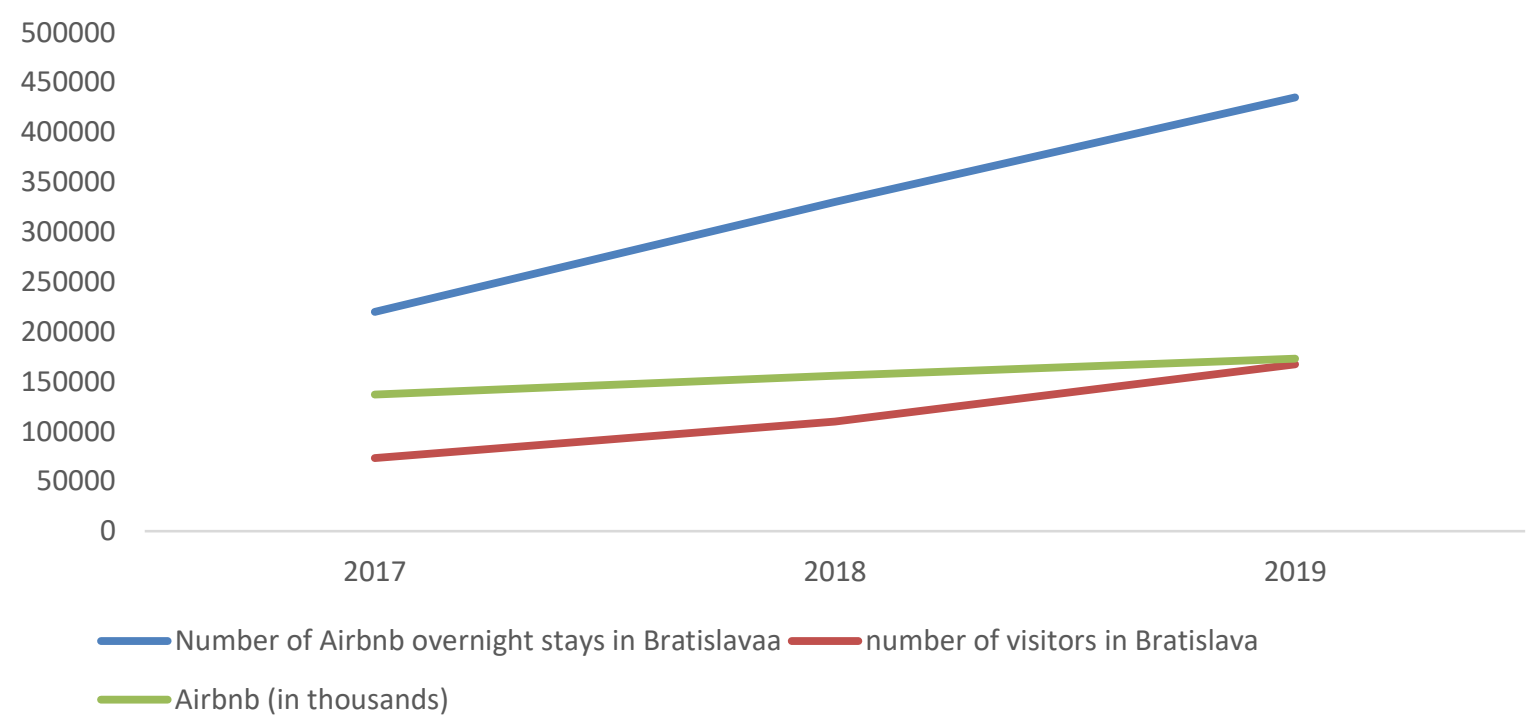

Source: own processing according to Koniar, 2019; Statista, 2021

During 2019, a total of 1,395,896 visitors visited Bratislava, who made 2,850,755 overnight stays, which is an average of 2.04 nights per visitor (VisitBratislava, 2020). Of this, $8.34 \%$ $(167,300)$ were visitors accommodated through Airbnb. Their share of overnight stays is $51.13 \%(435,000)$ (Koniar, 2019), which is an average of 2.6 nights per visitor.

Based on the above data, it can be concluded that shared accommodation occupies an important primary position in the accommodation statistics of the capital's tourism with a higher share of overnight stays than the total number of all overnight stays in other facilities. It can also be argued on the basis of the average number of overnight stays that participants in tourism in the capital prefer longer-term accommodation in shared accommodation over accommodation in other accommodation establishments. Other types of accommodation (such as hotels) usually provide a wide range of additional services and therefore the client's discomfort is certainly not the criterion for which tourists prefer to choose shared accommodation. But the price can be the criterion. In Tab. 2 we summarize the average price of shared accommodation in Bratislava within the observed period 01/11/2019 - 30/09/2020. 
Tab. 2 The average price of Airbnb in Bratislava from 01/11/2019 to 30/09/2020 (in EUR)

\begin{tabular}{|l|l|l|l|l|l|l|l|l|l|l|l|}
\hline Month & $\begin{array}{l}11 / \\
2019\end{array}$ & $\begin{array}{l}12 / \\
2019\end{array}$ & $\begin{array}{l}01 / \\
2020\end{array}$ & $\begin{array}{l}02 / \\
2020\end{array}$ & $\begin{array}{l}03 / \\
2020\end{array}$ & $\begin{array}{l}04 / \\
2020\end{array}$ & $\begin{array}{l}05 / \\
2020\end{array}$ & $\begin{array}{l}06 / \\
2020\end{array}$ & $\begin{array}{l}07 / \\
2020\end{array}$ & $\begin{array}{l}08 / \\
2020\end{array}$ & $\begin{array}{l}09 / \\
2020\end{array}$ \\
\hline Price & 48 & 56 & 47 & 43 & 39 & 34 & 35 & 39 & 42 & 49 & 45 \\
\hline
\end{tabular}

Source: Own processing according to Alltherooms (2021)

The graphical expression of the Tab. 2 is Fig. 3.

Fig. 3 Development of the average price of shared accommodation in Bratislava from $01 / 11 / 2019$ to $30 / 09 / 2020$ (in EUR)

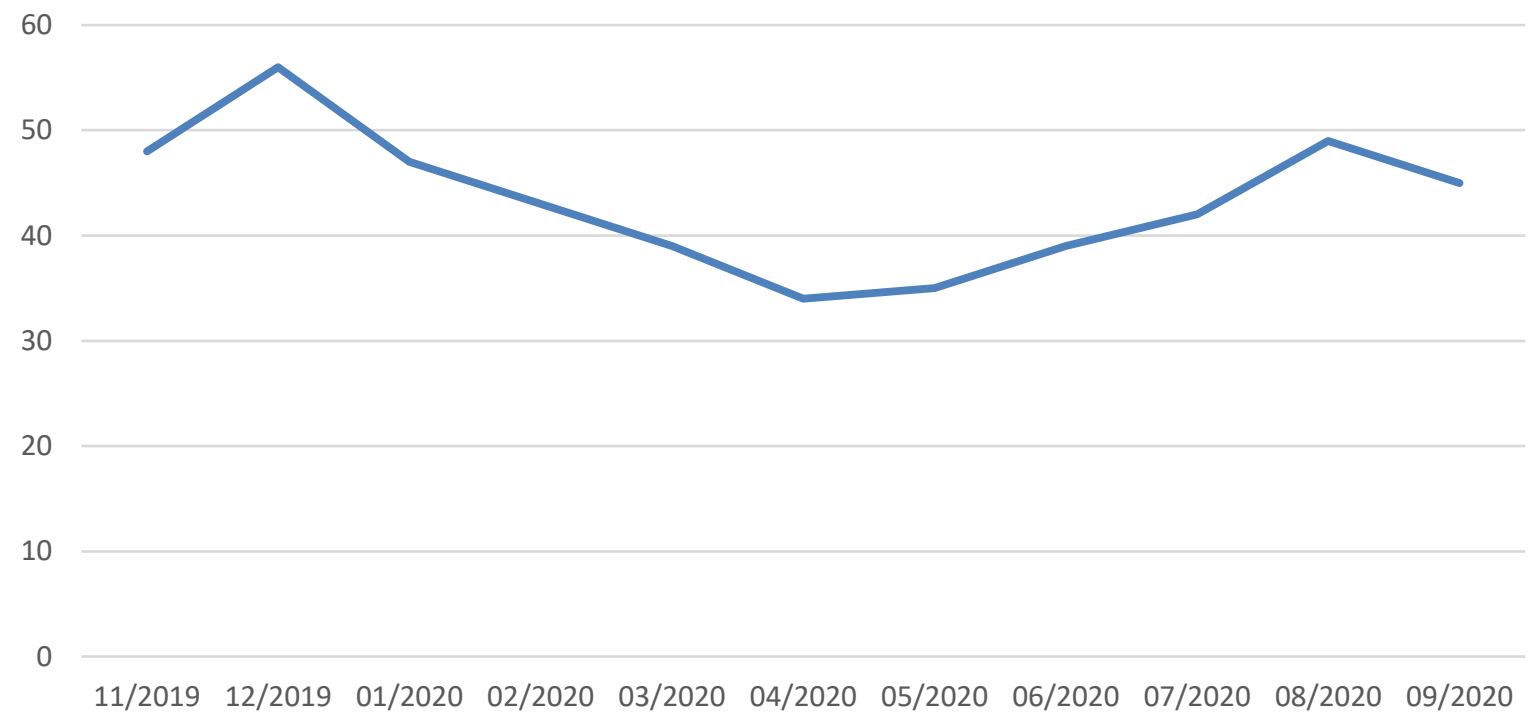

Source: own processing according to Alltherooms, 2021

During the monitored period from 01/11/2019 to 30/09/2020, Bratislava recorded 595985 visitors. The structure of increments on a monthly basis is shown in Tab. 4.

Tab. 4 Number of visitors to Bratislava from 01/11/2019 to 30/09/2020 (in thousands)

\begin{tabular}{|l|l|l|l|l|l|l|l|l|l|l|l|}
\hline Month & $\begin{array}{l}11 / \\
2019\end{array}$ & $\begin{array}{l}12 / \\
2019\end{array}$ & $\begin{array}{l}01 / \\
2020\end{array}$ & $\begin{array}{l}02 / \\
2020\end{array}$ & $\begin{array}{l}03 / \\
2020\end{array}$ & $\begin{array}{l}04 / \\
2020\end{array}$ & $\begin{array}{l}05 / \\
2020\end{array}$ & $\begin{array}{l}06 / \\
2020\end{array}$ & $\begin{array}{l}07 / \\
2020\end{array}$ & $\begin{array}{l}08 / \\
2020\end{array}$ & $\begin{array}{l}09 / \\
2020\end{array}$ \\
\hline $\begin{array}{l}\text { Number of } \\
\text { visitors }\end{array}$ & 117 & 120 & 87 & 81 & 27 & 2 & 7 & 21 & 46 & 53 & 36 \\
\hline
\end{tabular}

Source: own processing according to VisitBratislava, 2020

The graphical expression of the Tab. 4 is Fig. 5. 
Fig. 5 Development of the number of visitors to Bratislava from 01/11/2019 to 30/09/2020 (in thousands)

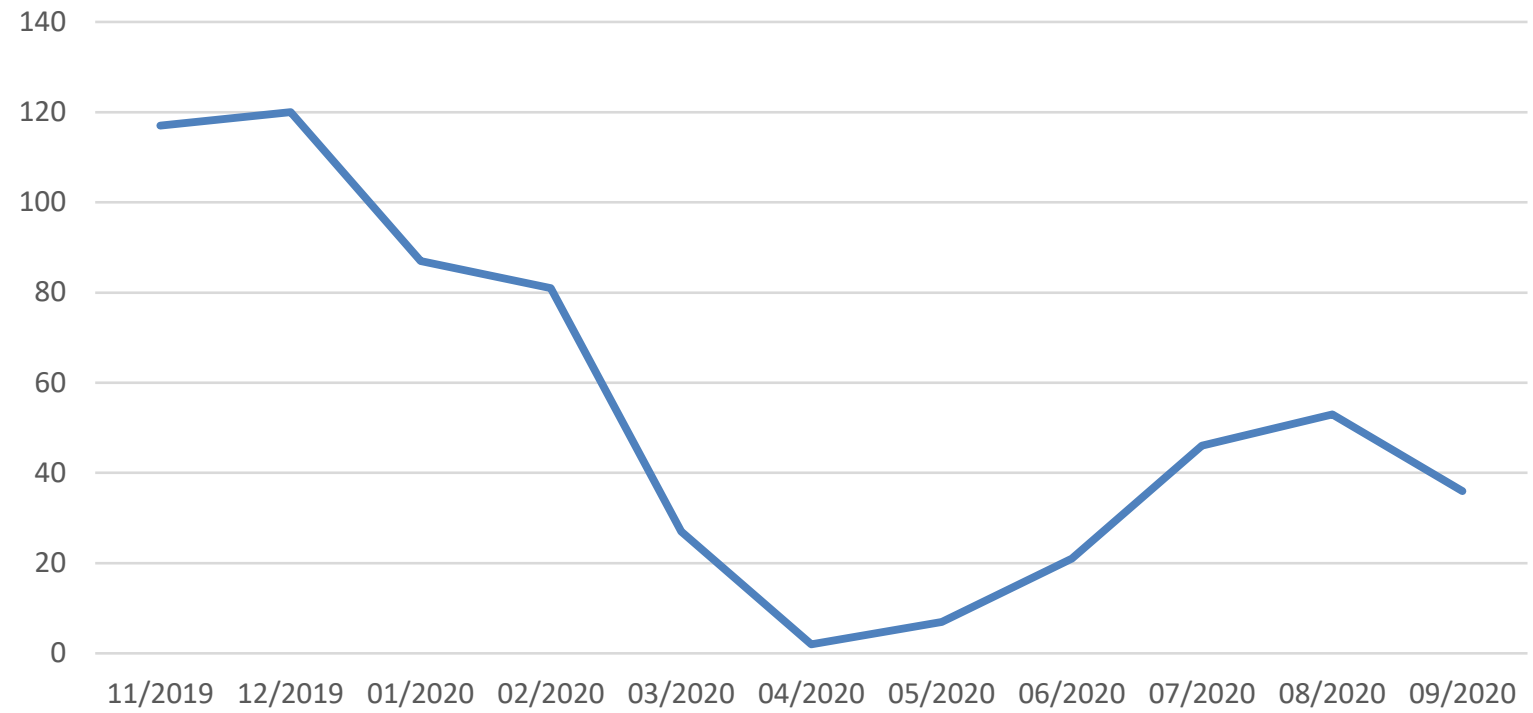

Source: Own processing according to VisitBratislava (2020)

Based on the summarized data, we approach the following sections of the paper to examine their relationships and analysis of dependencies through econometric models.

\section{METHODOLOGY}

The aim of the paper is to use econometric models to evaluate and explicitly express the relationship between the number of visitors to Bratislava and the average price of shared accommodation Airbnb in Bratislava.

In the paper, we initially apply general methods of data acquisition, which are analysis and deduction. The source of data are publications from databases of scientific journals, specialized statistical databases, theoretical articles, and research contributions of recognized experts focusing on the subject matter. We then select the information obtained based on their explanatory power, which leads to the creation of a relevant knowledge base, to which the part with the results of the paper can be linked.

In the part of the research results, we primarily deal with the summary of data on the number of visitors to Bratislava and the collection of data on the development of prices of shared accommodation in Bratislava. The data are then analysed in the next part using econometric models (specifically using regression and correlation analysis) and at the end of the article we derive the conclusions of the research.

The average price of shared Airbnb accommodation in Bratislava was determined for the dependent variable " $\mathrm{y}$ " and the number of visitors to Bratislava was determined for the independent variable " $x "$.

The data collection period was set at 01/11/2019 - 30/09/2020. This choice was made based on the data availability of the dependent variable.

The following hypothesis was established $\left(\mathrm{H}_{1}\right)$ :

$\mathbf{H}_{\mathbf{1}}$ : The number of visitors to Bratislava affects the average price of shared accommodation in Bratislava. 
The hypothesis is verified by ANOVA. In this part of the output of the econometric analysis, we test the null hypothesis $(\mathrm{HO})$, which states that the model by which we explain the dependencies (in the case of this paper it is a linear regression line) is, resp. is not suitable, and we subsequently accept, resp. rejects the alternative hypothesis claiming the opposite. To evaluate the statement, the output parameter "Significance F" (equal to the value of P-value of the dependent variable) is used, whose value (significance level) lower than 0.05 (or in our case even value lower than 0.001) says that the model was chosen correctly, we reject $\mathrm{HO}$ and accept the alternative hypothesis (in our case, a hypothesis expressing the existence of a relationship between a dependent and an independent variable). A value greater than 0.05 indicates that the slope of the regression line may be zero and that there is insufficient evidence at the $95 \%$ confidence level that there is a significant linear relationship between the dependent and independent variables.

Within the paper, we further examine the degree of causal (causal) dependence of the monitored variables through regression and correlation analysis. The first part of the output ("Regression Statistics" section) is the results of the correlation analysis. The closer the value of the correlation coefficient (Multiple R) is to 1 , the stronger the dependence of the positive relationship. Conversely, the closer this value is to -1 , the stronger the dependence of the negative relationship. The value of the correlation coefficient approaching 0 means that the intensity of the relationship between the dependent and independent variables recedes, resp. until it expires. Individual intervals can be monitored in Tab. 6 .

Tab. 6 Intervals of the dependence of correlation coefficient (Multiple R)

\begin{tabular}{|l|l|}
\hline Multiple $\mathrm{R}$ & A very strong positive relationship \\
\hline From $+0,70$ to +1 & Strong positive relationship \\
\hline From $+0,40$ to $+0,69$ & Slightly positive relationship \\
\hline From $+0,30$ to $+0,39$ & weak positive relationship \\
\hline From $+0,20$ to $+0,29$ & No or negligible relationship \\
\hline From $+0,01$ to $+0,19$ & No relationship (zero correlation) \\
\hline 0 & No or negligible relationship \\
\hline From $-0,01$ to $-0,19$ & weak negative relationship \\
\hline From $-0,20$ to $-0,29$ & Moderately negative relationship \\
\hline From $-0,30$ to $-0,39$ & Strong negative relationship \\
\hline From $-0,40$ to $-0,69$ & A very strong negative relationship \\
\hline From $-0,70$ to -1 & A very strong positive relationship \\
\hline
\end{tabular}

Source: own processing according to Vijalapuram, 2019

The value "R Square" $\left(R^{2}\right)$ (in the "Regression Statistics" output section) represents the coefficient of determination. This value, after multiplication by 100 , indicates that the regression line chosen by us explains the dependent variable to XY\%, and the other part (i.e. $X Z \%$ ) the unexplained variability below which the influence of other random factors and other unspecified influences can be imagined. Again, this is an indicator whose value approaching 1 represents a result with a high degree of accuracy. 
Formula 7 Calculation of the value of the coefficient of determination ( $R$ Square" $=\mathbf{R}^{\mathbf{2}}$ )

$\mathrm{R}^{2}=\frac{\text { regression sum of squares }}{\text { total sum of squares }}$

Source: Own processing according to Vijalapuram (2019)

\subsection{Limitations}

There is a limitation that could skew our results. As part of the examination of alternative hypotheses predicting regression, a minimum number of measured elements of eight $(\mathrm{N}=8)$ is recommended for a narrow data model (ie very low variation), and with a high variation of the variable, the minimum number of measured elements $N$ is shifted to twenty-five $(N \approx 25)$ (Jenkins \& Quintana-Ascencio, 2020). For the time period specified by us (01/11/2019 $30 / 11 / 2020$ ), based on the monthly periodicity of the monitored indicators, the amount of data collected is at the level of twelve or less, and therefore the results may be skewed. Therefore, we propose to carry out further research in the future to verify the results we have achieved on a larger set of data.

\section{RESULTS AND DISCUSSION}

Market equilibrium can be defined as a constantly renewing system of relations between territorial and time-varying demand at a certain price level, and the mismatch between supply and demand leads to inflationary pressures (Strážovská, 2016), i.e. a change in price. Finding a match between the supply and demand of shared accommodation and the subsequent change in the price of accommodation encouraged us to conduct our research, which is to examine the relationship between the number of visitors to Bratislava and the average price of shared Airbnb accommodation in Bratislava.

Fig. 8 Development of the average price of shared accommodation and the number of visitors for the territory of Bratislava in the period 01/11/2019 - 30/09/2020

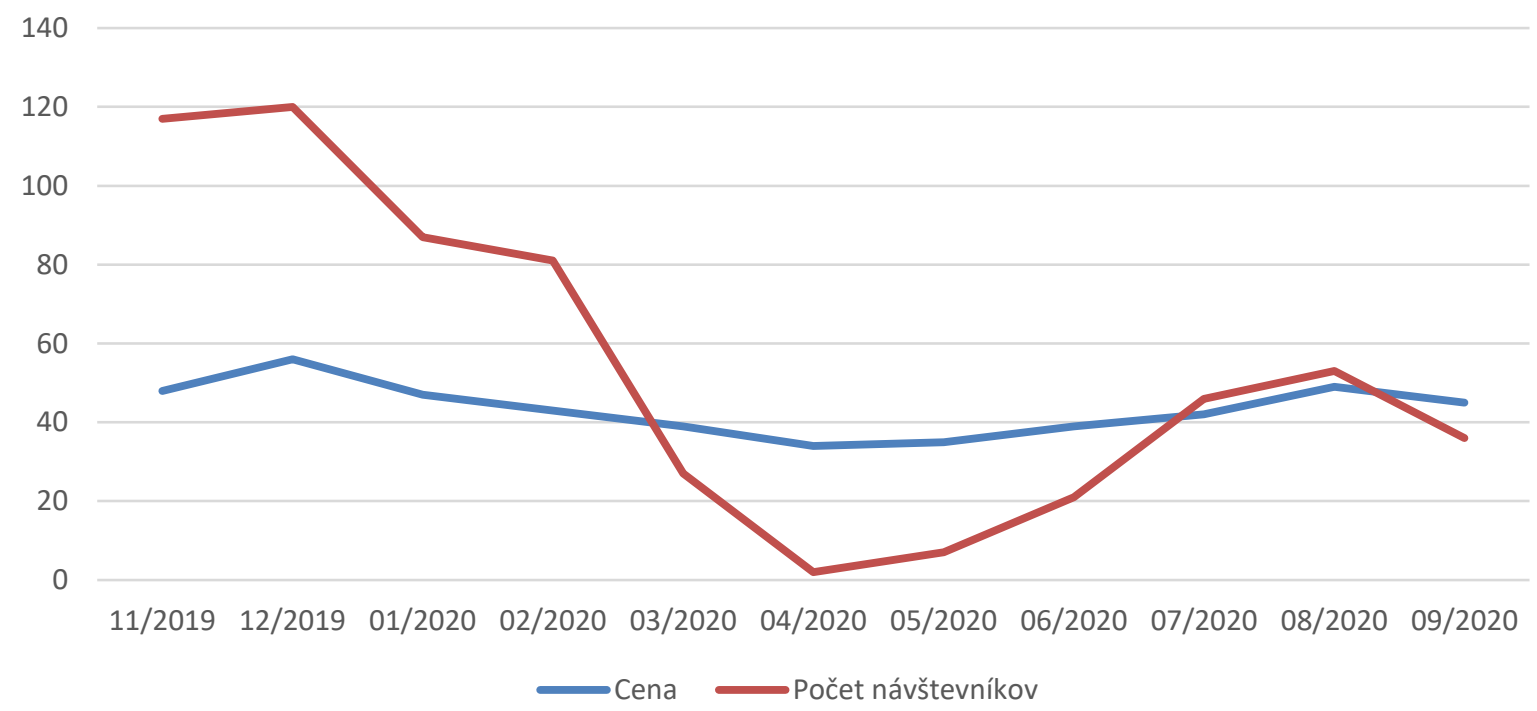

Source: own processing

Fig. 8 can be divided into four time periods in which the parallel direction of both variables can be monitored. In the period from $11 / 2019$ to $12 / 2019$, the growth of both indicators can be 
monitored. From $12 / 2019$ to $04 / 2020$, the values of both variables decrease. From $04 / 2020$ to $08 / 2020$ both variables re-record growth, and from 08/2020 until the end of the observed period (09/2020) we register a decrease in the values of both variables.

The average price curve copies the number of visitors curve. Based on this, it is possible to assume the occurrence of dependence and therefore we proceed to perform regression and correlation analysis in the next part of the paper.

In Tab. 9 we present the results of econometric analysis.

Tab. 9 Regression results for the number of visitors variable $(* * * \mathbf{p}<.001, * * \mathrm{p}<.01, *$ $\mathrm{p}<.05)$

\begin{tabular}{|l|l|l|l|}
\hline$X$ - variable & Correlation coefficient (P-value) & R2 & ANOVA (Significance F) \\
\hline number of visitors & $0,86828121 * * *$ & 0,75391227 & 0,00052704 \\
\hline
\end{tabular}

Source: own processing

As can be seen above, in the countries listed in Tab. 9 we register the dependence between the number of visitors to the capital and the average price of shared Airbnb accommodation in Bratislava. In this case, we assume that an increase in the number of visitors in the country will lead to an increase in the average price of shared accommodation in Bratislava and vice versa. Hypothesis $\mathrm{H} 1$ tested by us ("the number of visitors to Bratislava affects the average price of shared accommodation in Bratislava") is accepted based on the results of the analysis, as the ANOVA test results are lower than 0.05, which means that the selected model was correct (and We reject $\mathrm{HO}$ in these cases). In addition, the P-value for the locating constant (independent variable) is not only less than 0.05 , but less than 0.001 (in the table marked as "***" for $\mathrm{p}<.001$ ), which only emphasizes the significance of this coefficient. It can be interpreted that the number of visitors to Bratislava affects the average price of shared accommodation in Bratislava with a probability of error of less than $0.1 \%$.

The value of the correlation coefficient (Multiple $\mathrm{R}$ ) is 0.86828121 , which indicates a very strong positive relationship (Tab. 6). The last output of the econometric analysis is the coefficient of determination R Square (R2), which is equal to the value 0.75391227 . It can be interpreted as meaning that the regression function explains the variability of the average price of shared accommodation to $75.39 \%$ and the other part $(24.61 \%)$ is explained by the influence of other random factors and other unspecified influences.

The regression function has the form $y=0.00013628 x+35.9799282$, which means that with zero attendance in Bratislava, the average price of shared accommodation in the capital is at the level of 35.98 EUR. If the number of visitors increases by one unit of measure (one visitor), then the average price of shared accommodation will increase by 0.00013628 EUR. 
Fig. 10 Dependence of the average price of shared accommodation on the number of visitors

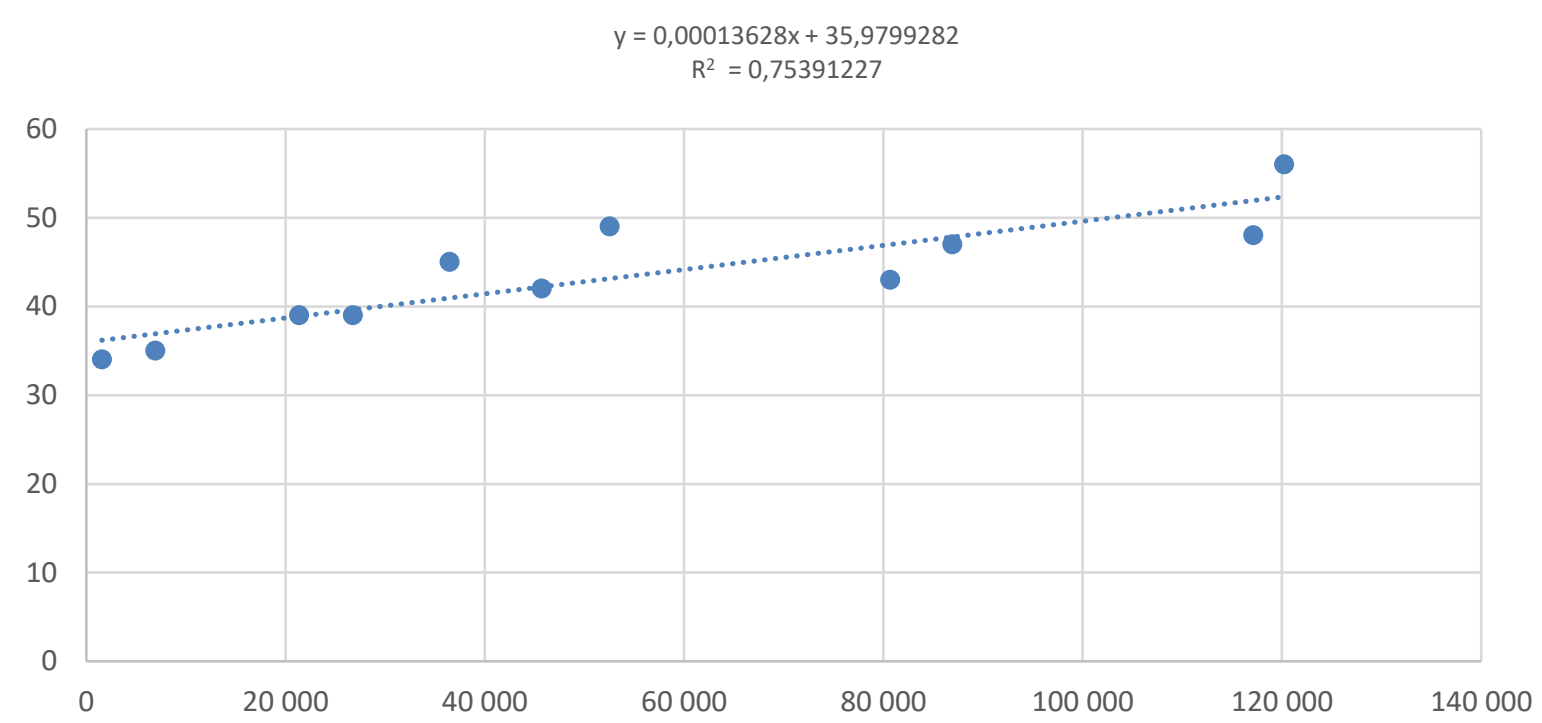

Source: own processing

\section{CONCLUSION}

In this paper, we examined changes in the average price of shared accommodation Airbnb in Bratislava caused by changes in the number of visitors to the city. To meet the goal of the paper, which was an explicit expression of the relationships between selected indicators, we chose the methodology of regression and correlation analysis under the conditions of using the ANOVA test, based on which we accepted the hypothesis.

It can be argued that the change in the number of visitors directly affects the average prices of shared accommodation in the capital, and to explicitly express this relationship, we also present the form of the regression function in the article.

Other industry factors can influence changes in the prices of shared accommodation both in Bratislava and in other tourist destinations where shared accommodation can be found, and therefore we propose to conduct similar research with other input data independently variable for example on the number of overnight stays in our chosen territorial unit of the capital of Slovakia - Bratislava.

\section{REFERENCES}

AlltheRooms. (2021). Bratislava. Retrieved 18 January 2021, from https://analytics.alltherooms.com/market/991512

Botsman, R. (2013). WacThe Sharing Economy Lacks A Shared Definition. Retrieved 20 April 2020, from https://www.fastcompany.com/3022028/the-sharing-economy-lacks-a-shareddefinition

Deane, S. (2020). 2020 Airbnb Statistic: Usage, Demographics, and Revenue Growth. Retrieved 19 December 2020, from https://www.stratosjets.com/blog/airbnb-statistics/

Dredge, D. \& Gyimóthy, Sz. (2015). The collaborative Economy and Tourism: Critical perspectives, questionable claims and silenced voices'. Tourism Recreation Research, 40(3), 286 - 302. https://doi.org/10.1080/02508281.2015.1086076 
Guttentag, D. (2013). Airbnb: disruptive innovation and the rise of an informal tourism accommodation sector. Current Issues in Tourism, 18(12). 1192 - 1217. https://doi.org/10.1080/13683500.2013.827159

Jenkins, D. \& Quintana-Ascencio, P. (2020). A solution to minimum sample size for regressions. PLOS ONE, 15(2), 1-15. San Francisco - Public Library of Science. https://doi.org/10.1371/journal.pone.0229345

Jung et al. (2016). Social or Financial Goals?: Comparative Analysis of User Behaviors in Couchsurfing and Airbnb. IN Proceedings of the $2016 \mathrm{CHI}$ Conference Extended Abstracts on Human Factors in Computing Systems (pp. 2857-2863). New York; Association for Computing Machinery. $\quad$ Retrieved 14 February 2021, from https://www.researchgate.net/publication/302074302_Social_or_Financial_Goals_Comparativ e_Analysis_of_User_Behaviors_in_Couchsurfing_and_Airbnb

Koniar, T. et al. (2019). Správa o činnosti Bratislavskej organizácie cestovného ruchu za rok 2018. Retrieved 15 December 2020, from https://zastupitelstvo.bratislava.sk/data/att/42916.pdf

PwC. (2015). The Sharing Economy: Consumer Intelligence Series. London : PricewaterhouseCoopers LLP.

Singh, S. R. \& Dem, H. (2011). Production Scheduling for Damageable Items with Demand and Cost Flexibility Using Genetic Algorithm. IN Proceedings of the International Conference on Soft Computing for Problem Solving (SocPros 2011), pp. 747-759. India; Springer.

Statista. (2021). Number of Airbnb overnight stays in the United States and Europe from 2015 to 2020. Retrieved 18 January 2021, from https://www.statista.com/statistics/795964/airbnbroom-nights-2015-2020/

Strážovská, H. Et al. (2016). Malé a stredné podnikanie. Bratislava : Sprint 2.

Sundararajan, A. (2014). Peer-to-peer Businesses and the Sharing (Collaborative) Economy: Overview, Economic Effects and Regulatory Issues. Retrieved 12 January 2021, from https://republicans-smallbusiness.house.gov/uploadedfiles/1-15-

2014_revised_sundararajan_testimony.pdf

Sundararajan, A. (2016). The Sharing Economy: The End of Employment and the Rise of Crowd-Based Capitalism. Cambridge : MIT Press.

Vijalapuram, S. (2019). How to read a Regression Table. Retrieved 15 January 2021, from https://www.freecodecamp.org/news/https-medium-com-sharadvm-how-to-read-aregression-table-661d391e9bd7-708e75efc560/

VisitBratislava. (2020). Štatistické ukazovatele za rok 2019. Retrieved 15 January 2021, from https://www.visitbratislava.com/wp-content/uploads/2020/02/\%C5\%A0tatistick\%C3\%A9ukazovatele-za-rok-2019-2.pdf

VisitBratislava. (2020). Turistické štatistiky v Bratislave - prvý až tretí kvartál 2020 Tourism statistics in Bratislava - first to third quarter of the year 2020. Retrieved 18 January 2021, from https://www.visitbratislava.com/wp-content/uploads/2021/01/Statistiky-I.-III.-kv.2020.pdf 